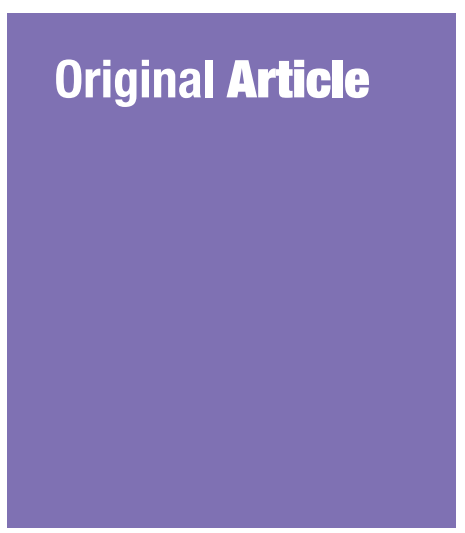

\title{
Knowledge and Attitude of Dental Students towards HIV/AIDS Patients in Melaka, Malaysia
}

\author{
Vijendra Pal Singh', Izni Syazana Osman², Nur Amanina RaHMAT ${ }^{3}$, \\ Nur Ashikin Aвu BaKaR ${ }^{4}$, Nurul Fathin Natasha Aвdul RaZAK \\ Sowmya NetTem ${ }^{1}$
}

Department of Periodontics, Faculty of Dentistry, Melaka Manipal Medical College (Manipal University), Melaka, Malaysia

Submitted: 5 Sep 2016 Accepted: 26 Apr 2017

2 Klinik Pergigian, Tanjung Sepat, Banting, Selangor, Malaysia

Online: 30 Jun 2017

3 Klinik Pergigian, Labis, Johor, Malaysia

$4 \quad$ Klinik Pergigian, Tapah, Perak, Malaysia

5 Klinik Pergigian, Telok Datok, Banting, Selangor, Malaysia

To cite this article: Singh VP, Osman IS, Rahmat NA, Abu Bakar NA, Abdul Razak NFN, Nettem S. Knowledge and attitude of dental students towards HIV/AIDS patients in Melaka, Malaysia. Malays J Med Sci. 2017;24(3):73-82. https://doi.org/10.21315/mjms2017.24.3.9

To link to this article: https://doi.org/10.21315/mjms2017.24.3.9

\begin{abstract}
Background: Cross contamination of HIV is a real threat today. Dental treatment often includes direct contact with a patient's blood and saliva, therefore dental professionals can be easily exposed to HIV microorganisms. Hence, it is essential to gain insight into dental students' knowledge and attitude towards HIV patients.

Method: A cross-sectional survey of 186 clinical year dental students (year 3, 4 and 5) in the 2015-2016 academic session at the Faculty of Dentistry, Melaka-Manipal Medical College (MMMC), Manipal University, Melaka volunteered to participate in the study. A self-administered questionnaire was used to determine their knowledge and attitude towards HIV/AIDS patients.

Results: Among 137 respondents (females $74.5 \%$ and males $25.6 \%$ ), $40.9 \%$ were Malay, 46.7\% were Chinese, $10.2 \%$ were Indian and $2.2 \%$ were others. The majority had an excellent (41.6\%) to good (56.2\%) knowledge and only (18\%) had a professional attitude. There was a statistically significant association of knowledge with gender $(P=0.009)$ and ethnicity $(P=$ $0.024)$, However, no association was found between attitude and gender $(P=0.756)$ or ethnicity $(P=0.792)$, or between knowledge and attitude $(P=0.473)$ of dental students.

Conclusion: Dental students' knowledge was not significantly associated with attitude. However, knowledge was associated with gender and ethnicity, but no association was found between age and knowledge and between age, gender, or ethnicity and attitude.
\end{abstract}

Keywords: attitude, dental, HIV/AIDS, knowledge, Malaysia, students 


\section{Introduction}

Infection with Human Immunodeficiency Virus Type 1 (HIV-1) and the resultant Acquired Immune Deficiency Syndrome (AIDS) is a major public health challenge in modern times (1). Since its first recognition in 1981, HIV/AIDS infection has become a major health concern worldwide. Global statistics (2) record that by the end of 2014, about 34.3-41.4 million people were living with HIV and approximately 1.2 million people had died from AIDS-related illnesses. Based on surveillance data, by the end of 2014 the cumulative number of HIV cases in Malaysia since the first case of HIV infection was reported in Malaysia in 1986 had reached 105,189, AIDS cases had reached 21,384, and there had been 17,096 deaths related to AIDS (3).

People living with HIV/AIDS are subject to a spectrum of potentially painful and healthcompromising oral conditions associated with HIV disease. Recent studies around the world indicate that oral lesions (e.g., oral candidiasis and Kaposi's sarcoma) occur in as many as $50 \%-70 \%$ of all HIV/AIDS cases. The oral health care setting has become a helpful environment for the early detection of HIV infection because most of its lesions present orally during the first stages of the disease. Therapeutic procedures in dentistry frequently involve blood and saliva that may contain a variety of blood-borne pathogens and microorganisms, such as HIV. Thus, dentists become a high-risk category for cross-contamination (4), most often by a needle prick injury, however, the risk of infection after precautionary exposure is only $0.3 \%$ (5). Research in countries such as South Africa, Brazil, Japan and Sudan have found dental students had insufficient knowledge about HIV, particularly in relation to its transmission (4).

Fear of transmission of this virus is one of the reasons why dentists refuse to treat patients with HIV infection (6). Willingness to treat HIV patients appears to be related to knowledge and disease process, recognition of oral manifestations, and understanding the modes of its transmission (7). Increased knowledge of HIV has led to an increased willingness and confidence of dentists and dental students to treat HIV-positive patients. Hence, it is essential to gain insight into dental students' knowledge levels and attitudes towards HIVpositive patients. This study was designed with the primary objective of assessing the knowledge and attitude towards HIV/AIDS patients among dental students in the Faculty of Dentistry,
Melaka-Manipal Medical College (MMMC), Melaka.

\section{Material and Method}

A cross-sectional survey was carried out from August to December 2015 at the Faculty of Dentistry, MMMC, Manipal University, Melaka, Malaysia. Taking the size of source population $(N=186)$ and margin of error (e-0.05), the sample size $(n)$ was calculated as 127 by using the Yamane formula. It was decided that the final sample size would include all clinical year (year 3, 4 and 5) dental students (186) who were enrolled at the Institute in the academic year 2015-2016, to allow for participant dropout. The study was approved by Institutional Research and Ethics Committee of the university. The purpose of the study was explained clearly and, a written consent was obtained from the students. All student participation in the study was voluntary and no incentive was given for completing the survey.

The survey instrument was selfadministered questionnaire in the English language, which had been previously used among dental students in Iran (4) and India (7). The questionnaire was made up of four parts.

1. Part I focused on the socio-demographic characteristics of the respondents, including gender, age, ethnicity, and batch.

2. Part II includes 18 close-ended questions related to knowledge of HIV/AIDS. A total knowledge score was obtained by adding the points given for each true/false question with each correct response scored as two [2] and incorrect responses scored as zero [o]. Hence, a student's total score could range from 0 to 36 .

The scores $(4,7)$ were interpreted into four segments:
a. <25\% - weak,
b. $25 \%-50 \%$ - moderate,
c. $51 \%-75 \%$ - good, and
d. $>75 \%$ - excellent level of knowledge.

3. Part III contained 15 questions about the oral manifestations of HIV/AIDS, with answer options of 'yes' or 'no'. 
4. Part IV comprised 17 questions addressing students' attitudes to HIV patients.

The answer to each question about attitude was rated on a five point Likert scale (strongly agree, agree, neutral, disagree, and strongly disagree) with a maximum possible score of 85 $(17 \times 5)$. The professional attitude scores were computed from 5 to 1 and negative attitude, conversely.

Attitude scores were interpreted in the following categories:

a. $>75 \%$ - positive,

b. $50 \%-75 \%$ - passive,

c. $<50 \%$ - negative.

Higher attitude scores were considered to indicate a professional attitude, and passive or negative scores were considered nonprofessional. The validity of the questionnaire was confirmed by a similar study and by Cronbach's alpha correlation coefficient $(\alpha=0.67)$, indicating a high degree of internal consistency (4).

Statistical analysis: Epi-Info 7 software was used for statistical analysis. Frequency and percentages were used to describe age, gender, ethnicity, knowledge and attitude. A Pearson chi-square test was used to assess the association between knowledge and attitude and to assess the association between knowledge level and attitude in relation to gender. The Fisher Exact Test was used to assess the association between knowledge level and attitude in relation to ethnicity as expected cell $<5$. $P$-value $\leq 0.05$ was considered significant.

We ran the Box-Tidwell (1962) procedure to determine whether the continuous independent variables were linearly related to the logit of the dependent variable. A Bonferroni correction was used for all variables in the model and statistical significance was accepted when $P<0.0071$. Based on this assessment, the continuous variable (age) was found to be linearly related to the logit of the dependent variables (knowledge and attitude). We applied multiple logistic regression model, and enter method was used.

\section{Results}

The overall response rate with a fully completed survey questionnaire was $72.1 \%$ ( $n=137)$. The mean age of respondents was $23.27(\mathrm{SD}=1.01)$ years. The socio-demographic characteristics are depicted in Table 1 . The total mean knowledge score was observed as $72.7 \%$, which indicated a good knowledge score. The proportion of the students' level of knowledge and attitude is described in Table 2, with $41.6 \%$ of students having excellent knowledge. The association of knowledge and attitude with gender and ethnicity is presented in Table 3 . There was a statistically significant association between knowledge and gender $(P=0.009)$, with a significantly high proportion (48\%) of female students having excellent knowledge. (Table 3). There was a significant association between knowledge scores and ethnicity $(P=0.024)$ with $64.3 \%$ of Indian students having excellent knowledge (Table 3).

The maximum correct response (98.5\%) was obtained for the question 'Needle stick injury can transmit HIV'. The least correct response (10.2\%) was for 'HIV/AIDS patients can be diagnosed with oral manifestations' (Table 6). Regarding oral manifestations, $99.3 \%$ of the students correctly identified oral candidiasis, 90.5\% for Kaposi's sarcoma, and $86.9 \%$ for Acute Necrotising Ulcerative Gingivitis (ANUG) (Table 7).

The overall mean attitude score observed was $69.1 \%$, a passive attitude. The majority of students $(81 \%)$ were found to have a passive (non-professional) attitude (Table 2). A positive (professional) attitude was found in 20\% and $17.6 \%$ of male and female students respectively, without any significant association $(P=0.756)$ between them (Table 3). The highest proportion of each ethnic groups having a non-professional attitude without any significant association between ethnicity and attitude $(P=0.792)$ (Table 3). Most of the students (89.1\%) disagreed or strongly disagreed with the statement that 'treatment of HIV/AIDS patients means wasting national resources', and this statement obtained the highest positive attitude score. In addition, the majority of students (90.5\%) agreed or strongly agreed with the statement that 'It is my right to know if my patients are infected by HIV', and this statement showed the highest negative attitude score (Table 8). No statistically significant association was found between excellent knowledge and professional attitude $(P=0.473)$ (Table 4).

The logistic regression model in regard to excellent knowledge was statistically significant, $\chi^{2}(5)=18.13, P<0.0005$. The model explained $16.7 \%$ (Nagelkerke $R^{2}$ ) of the variance in knowledge. There was significant association between gender, ethnicity and knowledge. 
Females were 3.48 times more likely to have excellent knowledge (95\% CI:1.33,9.13; $P=$ o.011). Compared to Malay students, Chinese students were 2.4 times more likely to have excellent knowledge (95\% CI:1.13,5.63; $P=$ o.043) and Indian students were 3.81 times more likely (95\% CI:1.05,13.77; $P=0.042$ ). However, there was no significant association between age and knowledge (Table 5).
The logistic regression model in regard to professional attitude was not statistically significant, $X^{2}(5)=1.161, P=0.949$. The model explained $1.4 \%$ (Nagelkerke $R^{2}$ ) of the variance in attitude. There was no significant association between age, gender, ethnicity and professional attitude (Table 5).

Table 1. Socio-demographic characteristics among the students $(n=137)$

\begin{tabular}{lc}
\multicolumn{1}{c}{ Variables } & $n(\%)$ \\
Age $($ years) & a \\
Gender & $23.27(1.01)$ \\
Male & $35(25.6)$ \\
Female & $102(74.5)$ \\
Ethnicity & \\
Malay & $56(40.9)$ \\
Chinese & $64(46.7)$ \\
Indian & $14(10.2)$ \\
Others & $3(2.2)$ \\
\hline
\end{tabular}

${ }^{\mathrm{a}} \operatorname{Mean}(\mathrm{SD})$

Table 2. Distribution of dental student's level of knowledge and attitude

\begin{tabular}{lc}
\multicolumn{1}{c}{ Variables } & $\begin{array}{c}\text { No of students } \\
n(\%)\end{array}$ \\
Knowledge & \\
Excellent & $57(41.6)$ \\
Good & $77(56.2)$ \\
Moderate & $3(2.2)$ \\
Weak & 0 \\
Attitude & \\
Negative & $1(0.7)$ \\
Passive & $111(81)$ \\
Positive & $25(18.3)$ \\
\hline
\end{tabular}


Original Article | Knowledge and attitude of dental students towards HIV/AIDS patients

Table 3. Association of knowledge/attitude with gender and ethnicity

\begin{tabular}{lccccc}
\multicolumn{3}{c}{ Knowledge } & & Attitude \\
\cline { 2 - 5 } & $\begin{array}{c}\text { Excellent } \\
n(\%)\end{array}$ & $\begin{array}{c}\text { Average } \\
n(\%)\end{array}$ & $\begin{array}{c}\text { P-value } \\
\text { Gender }\end{array}$ & $\begin{array}{c}\text { Professional } n \\
(\%)\end{array}$ & $\begin{array}{c}\text { Non-professional } \\
n(\%)\end{array}$ \\
Male & $8(22.9)$ & $27(77.1)$ & $0.009^{*}$ & $7(20)$ & $28(80.0)$ \\
Female & $49(48.0)$ & $53(52.0)$ & & $18(17.6)$ & $84(82.4)$ \\
Ethnicity & & & & \\
Chinese & $27(42.2)$ & $37(58.8)$ & $0.024^{\wedge}$ & $11(18.5)$ & $53(81.5)$ \\
Indian & $9(64.3)$ & $5(35.7)$ & & $2(14.3)$ & $12(85.7)$ \\
Malay & $18(32.1)$ & $38(67.8)$ & & $11(19.6)$ & $45(80.4)$ \\
Others & $3(100.0)$ & 0 & $1(33.3)$ & $2(66.7)$ \\
\hline
\end{tabular}

${ }^{*}$ Chi-square test, ${ }^{\wedge}$ Fisher exact test used as expected cell $<5 . P$-value $<0.05$ is significant.

Table 4. Association of knowledge and attitude

\begin{tabular}{lccc}
\multirow{2}{*}{ Knowledge } & \multicolumn{2}{c}{ Attitude } & P-value \\
\cline { 2 - 3 } & Professional & Non-professional & \\
Excellent & $12(21.1)$ & $45(78.9)$ & $0.473^{*}$ \\
Average & $13(16.3)$ & $67(83.8)$ & \\
\hline
\end{tabular}

${ }^{*}$ Chi square test; $P$-value $<0.05$ is significant.

Table 5. Multivariable logistic regression analysis for excellent knowledge and professional attitude

\begin{tabular}{|c|c|c|c|c|c|c|}
\hline & \multicolumn{2}{|c|}{ Excellent knowledge } & \multicolumn{4}{|c|}{ Professional attitude } \\
\hline & Adjusted OR & $95 \% \mathrm{CI}$ & $P$-value & Adjusted OR & $95 \% \mathrm{CI}$ & $P$-value \\
\hline Age & 1.18 & $0.81-1.71$ & 0.396 & 1.14 & $0.72-1.81$ & 0.579 \\
\hline \multicolumn{7}{|l|}{ Gender } \\
\hline Male & Reference & & & Reference & & \\
\hline Female & 3.48 & $1.33-9.13$ & 0.011 & 0.79 & $0.27-2.28$ & 0.662 \\
\hline \multicolumn{7}{|l|}{ Ethnicity } \\
\hline Malay & Reference & & & Reference & & \\
\hline Chinese & 2.4 & $1.03-5.63$ & 0.043 & 0.85 & $0.31-2.34$ & 0.756 \\
\hline Indian & 3.81 & $1.05-13 \cdot 77$ & 0.042 & 0.78 & $0.15-4.22$ & 0.776 \\
\hline
\end{tabular}

OR $=$ Odds ratio, $95 \% \mathrm{CI}=95 \%$ confidence interval. $P$-value $<0.05$ is significant. 
Table 6. Correct responses of students to knowledge statements about HIV/AIDS

\section{Knowledge Statement}

Correct

Response (\%)

HIV/AIDS patients can contaminate dental workers.

91.2

HIV/AIDS patients can be diagnosed with oral manifestations.

10.2

ELISA is a screening test for HIV infection.

87.6

62.8

91.2

Western blot is a definite test for HIV/AIDS diagnosis.

78.8

82.5

53.3

98.5

83.9

82.5

67.2

Infection control methods for Hepatitis B provide adequate protection against HIV transmission.

Medical staff are more prone for cross-contamination.

47.4

There is a lot of HIV in the saliva of HIV/AIDS patients.

92.0

HIV can be transmitted through aerosols by handpieces.

19.0

57.0

59.1

69.3

CPR for patients with AIDS can transmit HIV infection.

Table 7. Students' knowledge about oral manifestations of AIDS

\begin{tabular}{lc}
\multicolumn{1}{c}{ Oral Manifestations } & Correct Response (\%) \\
Oral candidiasis & 99.3 \\
Kaposi's sarcoma & 90.5 \\
ANUG & 86.9 \\
Major aphthous & 68.6 \\
Crohn's disease & 77.4 \\
Cytomegalovirus & 60.6 \\
Hairy leukoplakia & 89.1 \\
Severe periodontitis & 82.5 \\
Xerostomia & 50.4 \\
Salivary gland infection & 62.8 \\
Gingivitis & 69.3 \\
Herpes zoster & 60.6 \\
Herpes simplex & 60.6 \\
Condiloma & 29.2 \\
Papiloma & 41.6 \\
\hline
\end{tabular}


Original Article | Knowledge and attitude of dental students towards HIV/AIDS patients

Table 8. Students' attitudes towards patient with HIV/AIDS (\%)

\begin{tabular}{|c|c|c|c|c|c|}
\hline Attitude Statement & $\begin{array}{l}\text { Strongly } \\
\text { Agree }\end{array}$ & Agree & Neutral & Disagree & $\begin{array}{l}\text { Strongly } \\
\text { Disagree }\end{array}$ \\
\hline $\begin{array}{l}\text { Treatment of HIV/AIDS patients means wasting } \\
\text { national resources. }\end{array}$ & 2.9 & 1.5 & 6.6 & 38 & 51.1 \\
\hline $\begin{array}{l}\text { All dental patients should be considered } \\
\text { potentially infectious. }\end{array}$ & 46 & 38.7 & 11 & 4.4 & - \\
\hline $\begin{array}{l}\text { If I know that my friend has HIV, I end the } \\
\text { friendship. }\end{array}$ & - & 0.7 & 16.8 & 35 & $47 \cdot 5$ \\
\hline $\begin{array}{l}\text { Supporting HIV/AIDS patients improves } \\
\text { community health. }\end{array}$ & 35.8 & 51 & 8.8 & 1.5 & 2.9 \\
\hline $\begin{array}{l}\text { Dentists with HIV/AIDS should not be allowed to } \\
\text { treat patients. }\end{array}$ & 16.1 & 24.1 & 29.9 & 17.5 & 12.4 \\
\hline $\begin{array}{l}\text { HIV/AIDS patients should be treated at a } \\
\text { separate ward. }\end{array}$ & 10.2 & $34 \cdot 3$ & 31.4 & 20.4 & 3.6 \\
\hline $\begin{array}{l}\text { A blood test should be taken for diagnosis of HIV } \\
\text { in all dental patients. }\end{array}$ & 9.5 & 22.6 & 27.7 & 36.5 & 3.6 \\
\hline $\begin{array}{l}\text { I am morally responsible to treat HIV/AIDS } \\
\text { patients. }\end{array}$ & 24.8 & $53 \cdot 3$ & 18.3 & 2.9 & 0.7 \\
\hline $\begin{array}{l}\text { HIV/AIDS patients can live with others in the } \\
\text { same place. }\end{array}$ & 19.7 & 61.3 & 18.3 & 0.7 & - \\
\hline I am not obligated to treat HIV/AIDS patients. & 5.8 & 21.9 & 32.1 & 28.5 & 11.7 \\
\hline HIV/AIDS patients can lead a normal life. & 29.2 & 52.6 & 14.6 & 3.6 & - \\
\hline I can safely treat HIV/AIDS patients. & 16.8 & $45 \cdot 3$ & 27 & 9.5 & 1.5 \\
\hline I will treat HIV/AIDS patients. & 20.4 & 51.1 & 26.3 & 2.2 & - \\
\hline $\begin{array}{l}\text { My knowledge about infection control is enough } \\
\text { to treat HIV/AIDS patients. }\end{array}$ & 8.0 & 31.4 & 39.4 & 18.9 & 2.2 \\
\hline $\begin{array}{l}\text { I worry about being infected with HIV by my } \\
\text { patients. }\end{array}$ & 9.5 & 52.6 & 29.2 & 6.6 & 2.2 \\
\hline I will do CPR if HIV/AIDS patients need it. & 5.8 & $34 \cdot 3$ & $45 \cdot 9$ & 11 & 2.9 \\
\hline $\begin{array}{l}\text { It is my right to know if my patients are infected } \\
\text { by HIV. }\end{array}$ & 59.8 & 30.7 & 8.8 & 0.7 & - \\
\hline
\end{tabular}

\section{Discussion}

Health care professionals should have adequate knowledge of HIV/AIDS, and their attitude and behaviour should be proper to take care of such patients. Health care professionals acquire their knowledge and behaviour from their professional education. In our study, the mean knowledge score of the participants about HIV was good (72.7\%). However, it was lower in comparison to the excellent knowledge reported by Sadeghi and Hakimi (4) (82.1\%) and Aggarwal and Panat (7) (78.8\%).

It is notable that $98.5 \%$ of the students knew that needle stick injury could transmit HIV. Although the risk of HIV infection to health care workers after percutaneous exposure is very low
(0.3\%) (5), needle stick injuries can be a potential risk factor for the dental professional creating extreme psychological stress. Therefore, students need to be made aware of the proper protocols for prompt management of needle stick injury. Only $19 \%$ of the students agreed that HIV could be transmitted through aerosols produced by a high-speed air-rotor hand piece and ultrasonic scaler. This may be because reports (8) of HIV transmission through this route are very rare. A theoretical possibility exists if the aerosols contain the blood of the HIV-positive patient. The possibility of aspiration of oral fluids and blood from an infected patient into a dental unit waterline exist, and this could expose the microbes of previous patients to the clinician or a consecutive patient. 
About $78 \%$ of the students in this study agreed that dental workers could act as an intermediary for the transmission of HIV, which suggests that most students were aware of disease transmission. However, this number is considered low compared to studies conducted in India and Iran $(4,7)$. These findings clearly highlight the importance of teaching students about HIV disease transmission. Centre for disease control (CDC), in their 1992 report, suggested that sharps injuries were the more likely route of transmission. The majority of the students agreed or strongly agreed that all the patients should be considered potentially infectious. It is important that universal precautions are implemented through institutional policy and reinforced continuously at a regular interval so that they become the norm in the daily practice of clinicians.

As many as 40 oral manifestations of HIV have been reported. Providing proper dental care to HIV/AIDS patients necessitates good knowledge for recognition of the oral lesions associated with the disease. The results demonstrate that most of the students in this study were aware of the major oral manifestations of AIDS. Kaposi's sarcoma, oral candidiasis and hairy leukoplakia, three of the most common oral lesion in HIV-positive patients, were the most identified in our study. However, the students needed a broader knowledge of lesions less strongly associated with HIV such as condyloma, papilloma and xerostomia. Students should also be educated that even the lesions strongly associated with HIV/AIDS are not exclusive to HIV/AIDS. Kaposi's sarcoma, oral candidiasis, and hairy leukoplakia may also be seen in patients not infected with HIV/AIDS.

As the number of people with HIV/AIDS are increasing worldwide, the need of infected individuals for medical and dental care will increase. Dental practitioners should be required to enhance their knowledge of the disease and its oral manifestations. The dental curriculum in our institution involves theoretical classes on the manifestation of HIV/AIDS and infection control. However, additional education on HIV/AIDS should be implemented by the administration for the students. This could take form of conferences, workshops, seminars or continuous professional development.

The attitude of dental students towards patients with HIV/AIDS was non-professional (passive) in our study, with a mean attitude score of $69.08 \%$. The association of attitude with gender and ethnicity was non-significant. Our study showed higher attitude scores than studies reporting negative attitudes by Sadeghi and Hakimi (4) and $\mathrm{Hu}$ et al. (9). However, studies done by Aggarwal and Danat (7) and Seacat et al. (10) reported a positive attitude, with higher attitude scores than our study. The participant students in the present study had no previous exposure to treating HIV patients, and more than half of them were worried about being infected with HIV patients. This may explain the lack in confidence and passive attitude of students in our study. However, a positive attitude was observed in their willingness to treat and understand the moral responsibility to treat HIV patients.

In our study, $27.74 \%$ of the dental students agreed that they were not obligated to treat HIV/AIDS patients. These findings were comparatively low when compared with the findings reported by Sadeghi and Hakimi (4); Aggarwal and Panat (7). Since 1988, WHO has affirmed that all dental professionals must treat HIV patients (11). Dentists are ethically obligated to provide care for patients with infectious disease (12). Students' fear and concern about being infected with HIV may overpower their intellectual and practical ability to cope with the treatment and management of such patients.

With $71.5 \%$ of the students agreeing or strongly agreeing to treat HIV/AIDS patients and no students responding with 'strongly disagree', it is clear that they are prepared to provide dental treatment to all patients without discrimination. Proper knowledge and a professional attitude to giving care and managing potentially infectious patients may impact positively on the willingness of students to treat patients. In contrast to the present study, Kadeh et al. (6) and Al-Sandook et al. (13) reported that most dentists in their studies refused to treat this kind of patient. Current guidelines are that dentists must not refuse to treat a patient solely on the grounds of HIV infection, and they cannot legally refer these patients to speciality clinics for routine dental care (11).

More than half of the students (59.8\%) strongly agreed that they are entitled to know if their patients are infected by HIV. Similarly, in a study involving Thai dental practitioners, about $41.9 \%$ of respondents agreed with the statement 'You would feel angry if a patient told you he/ she has HIV/AIDS after the treatment' (14). As dentists are among the health-care providers who come in direct contact with patients' blood and other body fluids while performing 
Original Article | Knowledge and attitude of dental students towards HIV/AIDS patients

procedures, uncertainty about a patients' HIV status, the inadequacy or near total absence of appropriate safety facilities and a lack of clearly defined policies on the management of HIV/ AIDS in most health-care institutions present dentists with significant challenges and risks. Consequently, they are often uncomfortable attending to HIV/AIDS patients for fear of being infected, and it is not unusual therefore that some dentists are unwilling to offer treatment to HIV/AIDS patients (15).

In our study, the association between knowledge and attitude was not significant. These findings were in accordance with the studies done by Chew and Cheong (16). In our study, one participant was found to have excellent knowledge, however this participant's attitude was found to be negative. A lack of confidence in treating HIV patients may have amplified the participant's perceived risk of being infected with HIV. Knowledge was a significantly associated with gender and ethnicity in the present study, with females having better knowledge. In the study by Ahmed et al. (17), male students were more positive about both their competency and willingness to treat HIV patients, while females were more confident about their HIV/AIDS education. This was also observed in our study. Moreover, the proportion of female participants in our study was significantly higher than the male participants. Students from the different socio-religious, ethnicity and family backgrounds had different levels of exposure to knowledge.

The limitations of studies using crosssectional data such as in our study are that it measures HIV knowledge and attitude towards HIV patient at only one point in time. This knowledge and attitude may evolve with changes or exposure to HIV/AIDS-related information and new situations. We have not analysed other factors which can influence the knowledge and attitude such as years of experience in clinics and family background. Further longitudinal studies need to be carried out to address these limitations with larger sample sizes.

\section{Conclusion}

The findings of our study clearly show that the dental students had good knowledge, but a non-professional attitude towards HIV/ AIDS patients, with some inadequacy in their knowledge of disease transmission. Knowledge was significantly associated with gender and ethnicity, however no association was found between age and knowledge or between age, gender, ethnicity and attitude. In addition to this, no association was found between knowledge and attitude. Nevertheless, the results of this study should be interpreted carefully because we recruited dental students in their clinical years from only one institution in Malaysia. Thus, the external validity of our results is limited. Dentists could be the first practitioners to refer a patient to a medical counterpart if they have good knowledge of the oral manifestations of HIV and its modes of transmission. Thus, more collective effort should be given to improving the knowledge and attitude of future clinicians towards these patients in order to provide the best possible oral health care.

\section{Acknowledgement}

The authors would like to thank the Dean Faculty of Dentistry, Melaka Manipal Medical College, Manipal University, Professor Dr Abdul Rashid Hj Ismail for his constant support. We also wish to express our thanks to Associate Professor Dr Htoo Htoo Kyaw Soe for guiding the statically analysis during the course of this project. We also wish to express our appreciation to the dental students (Batch 3,4 and 5) for their participation in this study.

\section{Authors' Contributions}

Conception and design: VPS, NAR

Analysis and interpretation of the data: VPS, NAAB, NFNAR

Drafting of the article: VPS, ISO, NAR, NFNAR

Critical revision of the article for important intellectual content: VPS, ISO, NAR, SN

Final approval of the article: VPS, ISO

Statistical expertise: VPS, NAR, NAAB

Administrative, technical, or logistic support: NAAB, NFNAR, SN

Collection and assembly of data: ISO, NAR, NAAB, NFNAR

\section{Correspondence}

Dr Vijendra Pal Singh

Associate Professor

BDS (Manipal University), MDS (Manipal University), DICOI (Diplomate International Congress of Oral Implantologist, USA)

Department of Periodontics,

Faculty of Dentistry, 
Melaka Manipal Medical College (Manipal University) Jalan Batu Hampar, Bukit Baru

75150 Melaka, Malaysia.

Tel: +6 0176592243

Fax: +6 o6 2896669

E-mail: dr.vijendra@hotmail.com

\section{References}

1. Ozge T, Yesim S, Timucin B, Rabin S, Ata NY. Knowledge, attitudes and behavior of students from a medicine faculty, dentistry faculty, and medical technology vocational training school toward HIV/AIDS. Int $J$ Occup Med Environ Health. 2010;23(2):153-160.

2. Global Statistics UNAIDS. Fact sheetLatest statistics on the status of the AIDS epidemic. [Internet]. Geneva, Switzerland. Retrieved March 16, 2016 from http:// www.unaids.org/en/resources/campaigns/ HowAIDSchangedeverything/factsheet

3. Ngadiman $\mathrm{S}$, et al. National strategic plan for ending aids. Retrieved August 23, 2016 from http://www.moh.gov.my/images/gallery/Report/ MalaysiaNSPEA201620302.3(Final_27Nov)_ printed\%2Oversion.pdf

4. Sadeghi M, Hakimi H. Iranian dental students knowledge of and attitudes towards HIV/AIDS patients. $J$ Dent Educ. 2009;73(6):740-745.

5. Blignaut E. The role of the dental profession in the AIDS epidemic. $J$ Dent Assoc $S$ Afr. 1994;49(3):133-135.

6. Kadeh H, Saravani S, Golzari P. Knowledge, attitude and practice of dentists towards patients with HIV, hepatitis B and hepatitis C infections. Avicenna J Dent Res. 2014;6(1):1-6. https://doi. org/10.17795/ajdr-21348

7. Aggarwal A, Panat SR. Knowledge, attitude, and behavior in managing patients with HIV/AIDS among a group of Indian dental students. $J$ Dent Educ. 2012;77(9):1209-1217.

8. Henderson DK, Fahey BJ, Willy M, et al. Risk for occupational transmission of human immunodeficiency virus type 1 (HIV-1) associated with clinical exposures: a prospective evaluation. Ann Intern Med. 1990;113:740-746. https://doi. org/10.7326/00o3-4819-113-10-740
9. Hu SW, Lai HR, Liao PH. Comparing dental students' knowledge of and attitudes toward hepatitis B virus, hepatitis C virus, and HIVinfected patients in Taiwan. AIDS Patient Care STDS. 2004;18(10):587-593. https://doi. org/10.1089/apc.2004.18.587

10. Seacat JP, Inglehart MR. Education about treating patients with HIV infections/AIDS: the student perspective. J Dent Educ. 2003;67(6):630-640.

11. McCarthy G, Ssali C, Bednarsh H, Jorge J, Wangrangsimakul K, Page-Shafer K. Transmission of HIV in the dental clinic and elsewhere. Oral Dis. 2002;8(2s):126-135. https://doi.org/10.1034/j.1601-0825.8.s2.3.x

12. Jessri M, Fatemitabar SA. Implication of ethical principles in chair-side dentistry. Iran $J$ Allergy Asthma Immunol. 2007;6:53-59.

13. Al-Sandook T, Al-Naimi R, Younis M. An investigation of dentists' knowledge, attitude and practice towards HIV+ and patients with other blood borne viruses in Mosul city. Al-Rafidain Dent J. 2013;10(2):298-308.

14. Rungsiyanont S, Lam-ubol A, Vacharotayangul P, Sappayatosok K. Thai dental practitioners' knowledge and attitudes regarding patients with HIV. J Dent Educ. 2013;77(9):1202-1208.

15. Sallar AM. Correlates of misperceptions in HIV knowledge and attitudes towards people living with HIV/AIDS (PLWHAs) among in-school and out-school adolescents in Ghana. Afr Health Sciences. 2009;9(2):82-91.

16. Chew BH, Cheong AT. Ethnic groups difference in discriminatory attitude towards HIV/AIDS patients among medical students: A crosssectional study. Malaysian Journal of Medicine and Health Sciences. 2012;10(1):61-69.

17. Ahmed SI, Hassali MA, Aziz NA. An assessment of the knowledge, attitudes, and risk perceptions of pharmacy students regarding HIV/AIDS. Am $J$ Pharm Educ. 2009;73(1):15. https://doi. org/10.5688/aj730115 